\title{
Decomposição e ciclagem de nutrientes dos resíduos de quatro plantas de cobertura do solo
}

\author{
Nutrient cycling and decomposition of crop residues of four cover crops for soil \\ Michelle Barbosa Teixeira ${ }^{1}$, Arcângelo Loss ${ }^{2 *}$, Marcos Gervasio Pereira ${ }^{3}$, Carlos Pimentel ${ }^{4}$
}

\section{RESUMEN}

El mijo y el sorgo pueden ser utilizados como cultivos de protección para el suelo y el reciclado de nutrientes en suelos de baja fertilidad. Este estudio evaluó la descomposición y el ciclo de nutrientes en los residuos aéreos de cuatro plantas en un suelo arenoso, sin fertilizantes o riego. Los tratamientos consistieron en las plantas de mijo (cultivar ENA 2 BRS 1501), el sorgo (BRS 310) y malezas (MA). Las muestras conseguidas a los 87 días después de la siembra fueron estratificadas en hojas y tallos, colocadas y distribuidas en la superficie de las parcelas. La descomposición de la biomasa y la liberación de nutrientes fueron controladas mediante la acumulación de material, realizada 10, 20, 30, 60, 90 y 120 días después del corte. El mijo (ENA 2) acumuló la mayor cantidad de biomasa y materia seca en los tallos, mayor contenido de N, P y K en los residuos, seguido por sorgo, mijo (BRS 1501) y malezas. Con la excepción de $\mathrm{K}$, hubo una rápida liberación de nutrientes por parte de las malezas MA, mientras que en el mijo (ENA 2) la liberación fue más gradual. BRS1501 y el BRS 310 mostraron valores intermedios y similares. La mayor materia seca de ENA 2 y su mayor tiempo de descomposición indican que se recomienda su uso como cultivo de cobertura y para reciclaje de nutrientes.

Palabras claves: acumulación de nutrientes, la biomasa, mijo, sorgo, C/N.

\begin{abstract}
Pearl millet and sorghum can be used as cover plants for soil and recycling of nutrients in soils of low fertility. This study evaluated the nutrient cycling and decomposition of crop residues of four cover crops in sandy soil, without fertilizer or irrigation. The treatments consisted of two pearl millet genotypes (cultivar ENA 2 and BRS 1501), sorghum genotype BRS 310 and non-cultivated plants (weeds - VE). Samples of shoots, stratified into leaves and stems collected 87 days after planting were placed in bags and distributed on the surface of the plots. The dry matter decomposition and nutrient release were monitored through collection of material from the bags 10,20,30,60, 90 and 120 days after cutting. The ENA 2 showed the greatest amounts of biomass and dry weight of stems and higher levels of N, $P$ and $K$ in its remaining detritus, followed by sorghum, BRS 1501 and VE. With the exception of $K$, there was a rapid release of all nutrients by VE, while the ENA 2 nutrient release was more gradual, and was intermediate and similar for BRS 1501 and sorghum. The greater dry weight and slower decomposition of cultivar ENA 2 make it the recommended genotype for use as soil cover and nutrient recycling.
\end{abstract}

Key words: nutrient accumulation, biomass, pearl millet, grain sorghum, C/N relationship.

\section{Introdução}

Atualmente tem-se buscado sistemas de uso do solo que sejam embasados nos moldes do desenvolvimento sustentável, com vertentes econômicas, ecológicas e sociais. Como solução, tem-se estimulado a busca de alternativas de manejos de menor custo e maior produtividade que possibilitem pelo menos substituir parcialmente os fertilizantes químicos (Kliemann et al., 2006, Teixeira et al., 2011). O uso

1 Engenheira Agrônoma, Mestre em Fitotecnia pela Universidade Federal Rural do Rio de Janeiro (UFRRJ). BR 465, Km 7, Seropédica, RJ, CEP 23890-000. E-mail: michellebte@yahoo.com.br.

2 Engenheiro Agrônomo, Doutor em Agronomia-Ciência do Solo, UFRRJ, BR 465, Km 7, Seropédica, RJ, CEP 23890-000. E-mail: arcangeloloss@yahoo.com.br

3 Professor Associado III do Departamento de Solo, Instituto de Agronomia, UFRRJ. Br 465, Km 7, Campus da UFRRJ, Seropédica, RJ, CEP 23890-000. E-mail: gervasio@ufrrj.br

4 Professor Titular do Departamento de Fitotecnia, Instituto de Agronomia, UFRRJ, Br 465, Km 7, Seropédica, RJ, CEP 23890000. E-mail: greenman@amcham.com.br

* Autor para correspondência.

Fecha de Recepción: 12 Junio, 2011.

Fecha de Aceptación: 01 Diciembre, 2011. 
de plantas de cobertura, para produção de palhada, que aportam grandes quantidades de massa ao solo, associado ao menor revolvimento do mesmo, são medidas que podem reduzir os impactos ambientais adversos e acarretar em maior economia e eficiência na adubação, pois parte dos nutrientes requeridos podem ser supridos pelos nutrientes liberados por meio da decomposição gradativa da palhada das plantas de cobertura (Teixeira, 2010).

A introdução de culturas de cobertura com rusticidade, tolerância a estresses ambientais e elevada capacidade de produção de massa, como o milheto e o sorgo, entre outras, é viável, pois propicia a manutenção de resíduos culturais, além de diminuir a amplitude térmica e conservar melhor a umidade do solo (Brancalião e Moraes, 2008). Em decorrência da produção de palhada, pelas plantas de cobertura, tem-se o aumento dos teores de matéria orgânica na superfície do solo. Este aumento é fundamental para que sejam obtidas vantagens, como: melhoria dos atributos edáficos, diminuição das perdas de solo por lixiviação e erosão, retenção de nutrientes e fornecimento gradativo dos mesmos para as culturas comerciais, durante a decomposição (Carvalho et al., 2008, Teixeira et al., 2010).

O milheto e o sorgo apresentam multiplicidade de usos, devido a sua rusticidade e facilidade de manejo, podendo dessa forma, ser uma alternativa para a agricultura familiar, de subsistência e baixa aplicação de insumos (Teixeira, 2010), mas também em grandes extensões, serem utilizadas como produtoras de palhada no sistema plantio direto (Geraldo et al., 2002). Essas plantas de cobertura podem, portanto, ser indicadas para diversas regiões e condições de cultivo. Dessa forma, em pequenas propriedades pode-se utilizar estas culturas como forragem e pastejo, para animais, e também como plantas de cobertura para o solo, sendo conduzidas até o final do ciclo, aproveitando-se o grão para alimentação e fabrico de rações para animais, além da palhada, que pode ser deixada sobre o solo para posterior decomposição e liberação dos nutrientes (Torres et al., 2005, Boer et al., 2008, Teixeira, 2010).

A decomposição da massa vegetal é uma variável importante na ciclagem de nutrientes, que, por sua vez, está altamente relacionada com a capacidade de absorção das diferentes espécies de plantas de cobertura (Teixeira et al., 2010). A dinâmica dessa decomposição depende da composição do material vegetal, como a relação $\mathrm{C} / \mathrm{N}$, do volume de produção de massa, do manejo da cultura, como cobertura, da fertilidade e do $\mathrm{pH}$ do solo, da qualidade e quantidade dos nutrientes disponíveis e das condições climáticas (Alvarenga et al., 2001). Assim, estudos de campo, envolvendo a perda de massa e a liberação de nutrientes pela decomposição de resíduos vegetais, com enfoque na distribuição de nutrientes, nos vários compartimentos do sistema palhada-solo, ao longo do tempo, são essenciais para o entendimento desta dinâmica (Kliemann et al., 2006, Teixeira et al., 2010). Portanto, este trabalho teve como objetivo avaliar a decomposição e a ciclagem de nutrientes pela parte aérea de quatro plantas de cobertura em solo arenoso, sem adubação e irrigação.

\section{Material e Métodos}

O experimento foi conduzido em área do Campo Experimental do Departamento de Fitotecnia, da Universidade Federal Rural do Rio de Janeiro ( $22^{\circ} 45^{\prime} \mathrm{S}, 43^{\circ} 41^{\prime}$ W e $40 \mathrm{~m}$ de altitude), em Seropédica, RJ. O clima da região, segundo Köppen, é do tipo Aw (tropical), com verão quente e chuvoso e inverno seco. A precipitação total, a evaporação total e a temperatura média, durante a primeira etapa experimental, que ocorreu da semeadura ao corte final das plantas de cobertura (março a maio de 2009), foram de $273 \mathrm{~mm}, 281 \mathrm{~mm}$ e $24^{\circ} \mathrm{C}$, respectivamente. Na segunda etapa, ocorrida a partir da instalação (junho de 2009) até a retirada dos litter bags, da área experimental (outubro de 2009), a precipitação total, a evaporação total e a temperatura média foram de $305 \mathrm{~mm}, 283 \mathrm{~mm}$ e $22{ }^{\circ} \mathrm{C}$, respectivamente.

O solo da área experimental é um Argissolo Vermelho-Amarelo (Teixeira, 2010), apresentando textura franco-arenosa no horizonte $\mathrm{A}$, com $126 \mathrm{~g} \mathrm{~kg}^{-1}$ de silte, $786 \mathrm{~g} \mathrm{~kg}^{-1}$ de areia e $88 \mathrm{~g} \mathrm{~kg}^{-1}$ de argila. Antes da implantação do experimento, na área havia sido cultivado tangerina, seguido de soja, e por último, laranja e limão taiti, que receberam calagem e adubação na área de acordo com a análise de fertilidade do solo e necessidades das culturas (Teixeira, 2010). Após a retirada do cultivo de laranja e limão, a área experimental permaneceu em pousio por \pm 12 anos, e ao longo deste período foram feitas roçadas esporádicas, sendo o material roçado deixado sobre o solo. Para o experimento, as plantas de cobertura utilizadas foram as cultivares de milheto pérola ENA 2 e BRS 1501, um híbrido de sorgo granífero BRS 310 e a vegetação 
espontânea (VE), como testemunha. Na área da VE foi realizado um levantamento das principais plantas invasoras que se desenvolveram, sendo constatada a presença de espécies de diversas famílias, tais como Leguminosae, Gramineae, Cyperaceae, Convolvulaceae, Euphorbiaceae e Compositae.

O delineamento experimental utilizado foi o de blocos ao acaso, em esquema de parcelas subdivididas, com quatro repetições, totalizando 16 parcelas. As parcelas foram constituídas por quatro tratamentos (duas cultivares de milheto, um híbrido de sorgo e a área com VE) e as subparcelas por sete épocas de avaliação $(0,10,20,30,60,90$ e 120 dias). Cada parcela experimental tinha $3,0 \mathrm{~m}$ de largura por 4,0 $\mathrm{m}$ de comprimento, perfazendo uma área total de $12 \mathrm{~m}^{2}$. Nas parcelas, o milheto e o sorgo foram semeados em 7 linhas de $4 \mathrm{~m}$ de comprimento, respectivamente, distanciadas de 0,50 m entre si (população de 40.000 plantas ha ${ }^{-1}$, como proposto por Geraldo et al. (2002), sendo a área útil utilizada para o desenvolvimento do trabalho, na subparcela, de $1 \mathrm{~m}^{2}$ (4 plantas centrais distanciadas de $0,5 \mathrm{~m}$ entre plantas e $0,5 \mathrm{~m}$ entre linhas).

O experimento foi instalado no campo no dia $05 / 03 / 2009$. O plantio foi feito em covas de $2-3 \mathrm{~cm}$ de profundidade, e o número de sementes usadas para os milhetos foram de 5 a 7 sementes por cova, e para o sorgo, utilizaram-se de 2 a 3 sementes por cova. Aos 14 dias após o plantio, procedeu-se um desbaste, deixando-se apenas uma planta por cova, devido à maioria das plantas terem atingido o estádio de cinco folhas naquele momento, conforme proposto por Geraldo et al. (2002). O experimento foi conduzido sem adubação, e foi irrigado até os 14 dias após a semeadura, garantindo assim, que as plântulas passassem satisfatoriamente pelos estádios iniciais críticos ao seu desenvolvimento, sendo observadas neste período, plantas com uma média de 5 folhas, sendo 3 delas completamente expandidas. Deste ponto em diante, a água fornecida foi apenas decorrente das chuvas ocorridas durante a condução do experimento.

Ainda em relação ao período inicial de desenvolvimento das plantas de cobertura e até o momento da floração, foi feita uma capina manual nas parcelas de milheto e sorgo, com exceção da área com VE (pousio), para a remoção das plantas espontâneas. Esta prática foi realizada com o objetivo de minimizar a deposição do material vegetal oriundo destas plantas sobre o solo, antes do corte, para que não influenciassem na ciclagem de nutrientes.
A capina foi feita logo que as plantas espontâneas começaram a germinar, sendo retiradas com a raiz. Portanto, todo material vegetal depositado na superfície do solo foi proveniente da palhada das plantas de cobertura.

Para a avaliação da biomassa seca na maturação (área útil de $1 \mathrm{~m}^{2}$ ) e a avaliação da taxa de decomposição e liberação de nutrientes, todas as plantas de cobertura foram cortadas no dia 31/05/09, aos 87 DAP, com auxílio de uma roçadeira costal, sendo as plantas de coberturas acamadas manualmente em sua respectiva parcela. Todas as coberturas de solo apresentavam stand homogêneo no momento do corte. Em seguida, foram separadas as folhas e colmos, retirando-se as panículas, e o material permaneceu por 7 dias em ambiente arejado e fresco. Nas parcelas com vegetação espontânea, para realização da coleta do material vegetal, foi utilizado um quadrado metálico de $1 \mathrm{~m}^{2}$, lançado aleatoriamente, sendo coletado todo o material contido na área delimitada por este para a quantificação da biomassa.

Para avaliar a decomposição e liberação de nutrientes, utilizou-se o método das bolsas de decomposição (litter bags), confeccionadas com nylon com malha $2 \mathrm{~mm}$ de abertura, com dimensões de $0,20 \times 0,20 \mathrm{~m}$ e área interna de $0,04 \mathrm{~m}^{2}$, conforme descrito por Thomas e Asakawa (1993). Em cada litter bag foram acondicionados $50 \mathrm{~g}$ das plantas de cobertura (material fresco), sendo esta quantidade referente à proporção de folhas e colmos de cada material avaliado, conforme a Tabela 1 . Os $50 \mathrm{~g}$ de material colocados nos litter bag foram previamente testados de acordo com a capacidade dos litter bags, sendo esta massa acomodada uniformemente, na área útil de $0,04 \mathrm{~m}^{2}$, não ocasionando sobreposição dos materiais, que foram cortados em tamanhos iguais de $4 \mathrm{~cm}$. O material oriundo da VE, não foi separado em colmos e folhas, porque se apresentava bastante homogêneo em relação à massa total.

Os litter bags foram distribuídos uniformemente na superfície do solo de cada parcela, sob a palhada restante das plantas de cobertura, sendo dispostos 6 litter bags em cada parcela. A avaliação da decomposição e liberação de nutrientes foi monitorada por meio de uma seqüência de seis amostragens, sendo a primeira aos 10 dias após o corte (DAC), das plantas de cobertura ao final do ciclo, e as outras coletas aos 20, 30, 60, 90 e 120 DAC, respectivamente. 
Tabela 1. Massa fresca de folhas e colmos colocadas nos litter bags.

\begin{tabular}{lcc}
\hline Planta de cobertura & Colmos $(\mathrm{g})$ & Folhas $(\mathrm{g})$ \\
\hline ENA 2 & 30,54 & 19,46 \\
BRS 1501 & 22,53 & 27,47 \\
Sorgo & 20,78 & 29,22 \\
\hline
\end{tabular}

Em cada amostragem foi retirado um "litter bag" por parcela. O material, que foi retirado dos litter bags, foi limpo (retirando-se areia e outros materiais minerais) e seco em estufa de circulação de ar forçada $\left(65^{\circ} \mathrm{C}\right.$ até peso constante), para obtenção da matéria seca remanescente. O material vegetal coletado por ocasião do corte (tempo zero) e o coletado dos litter bags aos 10, 20,30,60,60, 90 e 120 DAC, foram triturados em moinho tipo Willey, sendo posteriormente realizada a análise química de conteúdo em N, P e K. Primeiramente, foi feita a digestão sulfúrica do material vegetal e, no extrato vegetal analisaram-se os nutrientes. O N foi determinado por destilação por arraste à vapor (Tedesco et al. (1995), o $\mathrm{P}$ por colorimetria, o K por fotometria de chama (Malavolta et al., 1997). Também foi determinada a relação $\mathrm{C} / \mathrm{N}$ e os teores de lignina e holocelulose (Teixeira, 2010), das plantas de cobertura no tempo zero (após o corte na maturação), e o acúmulo dos nutrientes em estudo na parte aérea das plantas de cobertura até os 120 dias após o corte, sendo este obtido pelo produto da massa seca com o teor dos nutrientes.
Para descrever a decomposição dos resíduos vegetais e a liberação dos macronutrientes, foi aplicado o modelo matemático exponencial do tipo $\mathrm{X}=\mathrm{Xo}{ }^{\exp (-\mathrm{kt})}$, em que $\mathrm{X}$ é a quantidade de massa seca remanescente após um período de tempo t, em dias, Xo é a quantidade inicial de massa seca ou de nutriente, e k é a constante de decomposição do resíduo (Thomas e Asakawa,1993). Com o valor de k, foi calculado o tempo de meia-vida $\left(\mathrm{T}^{1 / 2}=0,693 / \mathrm{k}\right)$, que expressa o período de tempo necessário para que metade dos resíduos se decomponha ou para que metade dos nutrientes contidos nos resíduos seja liberada (Paul e Clark, 1989).

Os dados obtidos foram submetidos à análise de variância com aplicação do Teste $F$ entre os tratamentos. Havendo significância, os valores médios, para os tratamentos, foram comparados entre si pelo teste de Tukey a 5\%. Para cada planta de cobertura foram ajustadas equações de regressão, relacionando a quantidade média dos nutrientes reciclada em função da quantidade de matéria seca produzida para cada cultura, utilizando o Software Sigma Plot 8.0.

\section{Resultados e Discussão}

\section{Massa fresca e seca de folhas e colmos colocadas nos litter bags (tempo zero)}

Na Tabela 2 verificam-se os valores de massa seca de folhas e colmos provenientes dos $50 \mathrm{~g}$ de massa verde das plantas de cobertura no momento

Tabela 2. Massa seca de folhas e colmos colocadas nos litter bags (tempo zero) e conteúdo de água presente nas folhas e colmos na época da maturação.

\begin{tabular}{lccc}
\hline \multirow{2}{*}{ Planta de cobertura } & \multicolumn{3}{c}{ Massa seca de folhas e colmos $(\mathrm{g})$} \\
\cline { 2 - 4 } & Folhas $(\mathrm{g})$ & Colmos $(\mathrm{g})$ & Folhas + Colmos $(\mathrm{g})$ \\
\hline ENA 2 & $11,79 \mathrm{~b}$ & $19,24 \mathrm{a}$ & $31,03 \mathrm{a}$ \\
BRS 1501 & $16,36 \mathrm{a}$ & $13,38 \mathrm{~b}$ & $29,74 \mathrm{a}$ \\
Sorgo & $15,57 \mathrm{a}$ & $10,82 \mathrm{~b}$ & $26,39 \mathrm{~b}$ \\
VE & ----- & ------ & $22,89 \mathrm{c}$ \\
\hline & & Conteúdo de água $(\mathrm{g})$ & Massa total de H2O (g) \\
\hline & Folhas $(\mathrm{g})$ & Colmos (g) & $18,97 \mathrm{~d}$ \\
\hline ENA 2 & $6,26 \mathrm{c}$ & $12,71 \mathrm{a}$ & $20,26 \mathrm{c}$ \\
BRS 1501 & $9,52 \mathrm{~b}$ & $10,74 \mathrm{~b}$ & $23,61 \mathrm{~b}$ \\
Sorgo & $12,99 \mathrm{a}$ & $10,74 \mathrm{~b}$ & $27,11 \mathrm{a}$ \\
VE & ----- & ------ & \\
\hline
\end{tabular}

Médias seguidas de letras diferentes na coluna diferem entre si pelo teste de Tukey a $5 \%$. 
do corte na maturação (Tabela 1) que foram colocadas nos litter bags (tempo zero). Observa-se que o milheto ENA 2 apresentou o menor valor de massa seca para folhas e maior para colmos, quando comparado com o BRS 1501 e o sorgo. Em relação ao total de folhas e colmos, os milhetos apresentam os maiores valores de massa seca e a VE, o menor.

Em relação ao conteúdo de água nas folhas, o sorgo apresentou o maior valor e o ENA 2, o menor (Tabela 2). Já nos colmos, o ENA 2 se destaca com o maior conteúdo de água, e para o somatório de folhas e colmos, a VE apresentou os maiores conteúdos de água e o ENA 2, os menores. O maior conteúdo de água, assim como a estratificação das plantas de coberturas em folhas e colmos, auxilia no entendimento da dinâmica de decomposição dos resíduos culturais (milheto e sorgo), pois pode-se relacionar características, tais como teores de lignina e relação $\mathrm{C} / \mathrm{N}$, com a proporção de massa seca e de água, em cada parte das plantas de cobertura, e verificar como se comporta a decomposição destas plantas (Redin, 2010, Teixeira et al., 2011).

\section{Aporte e decomposição dos resíduos vegetais}

Entre as plantas de cobertura, a cinética de decomposição dos resíduos culturais apresentou um padrão semelhante, observando-se um progressivo decréscimo da massa seca, sendo este mais acentuado para a VE, quando comparada com as demais plantas de cobertura (Figura 1). O milheto ENA 2 apresentou maiores quantidades $(p>0,05)$ de massa seca remanescente, dentre as plantas de coberturas estudadas, em todas as épocas avaliadas, e a VE apresentou padrão inverso, com os menores valores de massa seca remanescente, em todas as

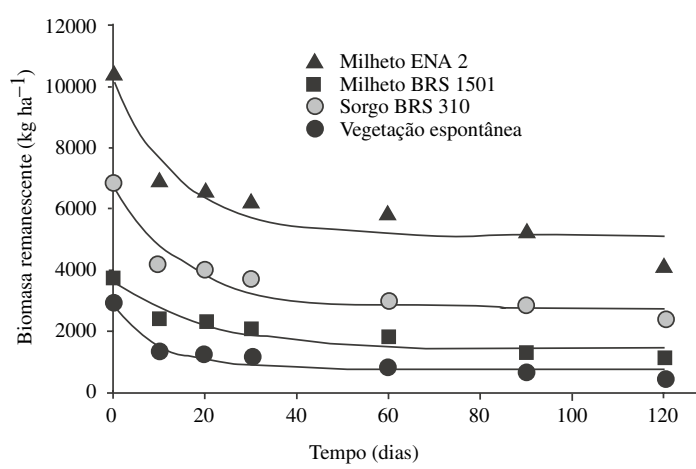

Figura 1. Biomassa seca remanescente das plantas de cobertura em avaliações realizadas no campo até 120 dias após a distribuição dos litter bags na superfície do solo.

épocas de avaliação. Entre o BRS 1501 e o sorgo, este último apresentou maiores quantidades de massa seca remanescente em todas as épocas avaliadas (Figura 1).

O maior tempo de meia vida $\left(\mathrm{T}^{1 / 2}\right)$ foi verificado para o milheto ENA 2, com 105 dias, seguido do sorgo, com 75 dias, o BRS 1501, com 70 dias e a $\mathrm{VE}$, com 34 dias, o menor $\mathrm{T}^{1 / 2}$ dentre as plantas de cobertura (Tabela 3). O menor $\mathrm{T}^{1 / 2}$ da VE está relacionado com sua composição (mistura de várias famílias, dentre elas, gramíneas e leguminosas), propiciando uma relação $\mathrm{C} / \mathrm{N}$ de 11 (Tabela 3), a menor entre as plantas estudadas e, desta forma, favorecendo a decomposição mais rápida dos resíduos vegetais da VE. Enquanto o sorgo e o BRS 1501 não apresentaram diferenças para a relação $\mathrm{C} / \mathrm{N}$, sendo estes valores iguais a 15 e 14 , respectivamente, e o ENA 2 apresentou a maior relação $\mathrm{C} / \mathrm{N}$, com valor de 29 .. Os valores da relação $\mathrm{C} / \mathrm{N}$ das plantas de cobertura corroboram os valores de $\mathrm{T}^{1 / 2}$ encontrados.

Tabela 3. Tempo de meia vida ( $\left.\mathrm{T}^{1 / 2}\right)$, constante de decomposição $(\mathrm{k})$, valores de $\mathrm{r}^{2}$ ajustados, relação C/N, teores de lignina e holocelulose e teor de $\mathrm{N}$ no tempo zero.

\begin{tabular}{lccccccc}
\hline \multirow{2}{*}{$\begin{array}{l}\text { Plantas de } \\
\text { cobertura }\end{array}$} & \multicolumn{2}{c}{ Parâmetros da equação de decomposição } & $\mathrm{C} / \mathrm{N}$ & Lignina & $\begin{array}{c}\text { Holo } \\
\text { celulose }\end{array}$ & Teor de N \\
\cline { 2 - 8 } & $\mathrm{k}$ & $\mathrm{T} 1 / 2$ & $\mathrm{r}^{2}$ & ---- & & $\mathrm{g} \mathrm{kg}^{-1}$ \\
\hline ENA 2 & $0,0066^{*}$ & 105 & $0,72^{*}$ & $29 \mathrm{a}$ & $322,2 \mathrm{a}$ & $664,5 \mathrm{~b}$ & $17,1 \mathrm{~d}$ \\
BRS 1501 & $0,0099^{*}$ & 70 & $0,83^{*}$ & $14 \mathrm{~b}$ & $321,9 \mathrm{a}$ & $629,1 \mathrm{~b}$ & $24,2 \mathrm{~b}$ \\
Sorgo & $0,0092^{* *}$ & 75 & $0,75^{* *}$ & $15 \mathrm{~b}$ & $263,3 \mathrm{~b}$ & $622,9 \mathrm{~b}$ & $20,9 \mathrm{c}$ \\
VE & $0,0204^{* *}$ & 34 & $0,72^{* *}$ & $11 \mathrm{c}$ & $192,2 \mathrm{c}$ & $732,0 \mathrm{a}$ & $29,4 \mathrm{a}$ \\
\hline
\end{tabular}

Médias seguidas de letras diferentes na coluna diferem entre si pelo teste de Tukey a $5 \% * \mathrm{e}^{* *}$ foram significativos a 5 e $1 \%$ pelo teste de Tukey. 
Aliado aos valores de relação $\mathrm{C} / \mathrm{N}$ das plantas de cobertura, destacam-se os teores de lignina e holocelulose (Tabela 3), verificando-se que os milhetos, ENA 2 e BRS 1501, apresentaram os maiores teores de lignina, seguidos do sorgo e da VE, com os menores teores deste elemento neste último. Para a holocelulose, observaram-se maiores valores para a VE, não sendo verificadas diferenças para os teores das demais plantas de cobertura (Tabela 3). A holocelulose pode ser considerada o conjunto de hemicelulose mais celulose (Redin, 2010).

Portanto, o maior $\mathrm{T}^{1 / 2}$ verificado para o ENA 2 está relacionado à maior relação $\mathrm{C} / \mathrm{N}$, ao menor teor de N, ao maior teor de lignina (Tabela 3) e menor conteúdo de água (Tabela 2). Apesar dos teores de lignina do ENA 2 não diferiram do BRS 1501 , verificou-se uma maior relação $\mathrm{C} / \mathrm{N}$ para o ENA 2 e, também, maior proporção de colmos (62\%) em relação à proporção de folhas (38\%). Já para o BRS 1501, observou-se relação inversa, com maior proporção de folhas (55\%) em detrimento de colmos (45\%) (Tabela 2). Em relação à massa seca de colmos, em um experimento anterior, o ENA 2 produziu $6534 \mathrm{~kg} \mathrm{ha}^{-1}$ e o BRS 1501, $1708 \mathrm{~kg} \mathrm{ha}^{-1}$ (Teixeira, 2010). Diante desses dados, conclui-se que o maior $\mathrm{T}^{1 / 2}$ para massa seca do ENA 2 está relacionado à sua maior relação $\mathrm{C} / \mathrm{N}$, aos maiores teores de lignina e maior produção de colmos. Com colmos mais lignificados e maior relação $\mathrm{C} / \mathrm{N}$ (menor teor de $\mathrm{N}$ na maturação), sua decomposição é mais lenta quando comparada ao BRS 1501 e às demais plantas de cobertura.

Entre as plantas de milheto BRS 1501 e o sorgo, não foram verificadas diferenças para a massa seca de folhas e colmos (Tabela 2), nem tampouco para a relação C/N (Tabela 3), mas o BRS 1501 apresentou maiores teores de lignina $\left(322 \mathrm{~g} \mathrm{~kg}^{-1}\right)$ que o sorgo $\left(263 \mathrm{~g} \mathrm{~kg}^{-1}\right)$. Diferindo do observado em outros estudos (Torres et al., 2005, 2008, Boer et al., 2008), o milheto BRS 1501 não apresentou maior $\mathrm{T}^{1 / 2}$ para sua massa seca, comparado ao sorgo, sendo os valores semelhantes entre estas duas plantas de coberturas, 75 dias para o sorgo e, 70 dias para o BRS 1501. Estes resultados podem ser decorrentes do BRS 1501 apresentar maiores teores de $\mathrm{N}$ em sua palhada $\left(24,2 \mathrm{~g} \mathrm{~kg}^{-1}\right)$ quando comparado ao sorgo $\left(20,9 \mathrm{~g} \mathrm{~kg}^{-1}\right)$ (Tabela 3). A maior disponibilidade de $\mathrm{N}$ favorece a atividade microbiana, o que acarreta em maior velocidade de decomposição da palhada (Gama-Rodrigues et al., 2007).
Para a VE, além de esta ter apresentado a menor relação $\mathrm{C} / \mathrm{N}$, também verificaram-se menores teores de lignina (192 $\mathrm{g} \mathrm{kg}^{-1}$ ) e maiores teores de holocelulose $\left(732 \mathrm{~g} \mathrm{~kg}^{-1}\right)$ e de $\mathrm{N}\left(29,4 \mathrm{~g} \mathrm{~kg}^{-1}\right)$, dentre as demais plantas de cobertura. A lignina é mais resistente à decomposição quando comparada a holocelulose (Sylvia et al., 1998). Portanto, os maiores teores de holocelulose e de $\mathrm{N}$ na VE favorecem a rápida decomposição de seus resíduos vegetais $\left(\mathrm{T}^{1 / 2}=34\right.$ dias) pela biota do solo. Associado a estas características, tem-se a homogeneidade dos materiais constituintes da VE com maior conteúdo total de água, pois os mesmos apresentaram caules tenros e muitas folhas, sendo estes materiais de decomposição mais fácil, quando comparados com as demais plantas de cobertura.

Em relação aos teores de nitrogênio $(\mathrm{N})$, sua liberação por meio da decomposição dos resíduos vegetais foi mais gradativa para o milheto ENA 2 (Tabela 3), com $\mathrm{T}^{1 / 2}$ de 103 dias e mais rápida para a VE, com $\mathrm{T}^{1 / 2}$ de 13 dias. O BRS 1501 e o sorgo apresentaram padrão intermediário, com $\mathrm{T}^{1 / 2} \mathrm{de}$ 76 dias para o sorgo e 72 dias para o BRS 1501 (Tabela 3). A liberação mais rápida de $\mathrm{N}$ pela palhada da VE está associada ao maior conteúdo de água e a menor relação $\mathrm{C} / \mathrm{N}$, já o milheto ENA 2 apresentou padrão contrário a este, com maior relação $\mathrm{C} / \mathrm{N}$ e menores conteúdos de água e quando comparado com o BRS 1501 e o sorgo, o ENA 2 apresentou maior massa de colmos. Estas características conferem o padrão de $\mathrm{T}^{1 / 2}$ do $\mathrm{N}$ apresentado. Entre o BRS 1501 e o sorgo, a similaridade apresentada para $0 \mathrm{~T}^{1 / 2}$ é devida à semelhança entre a massa de colmos e folhas e também a relação $\mathrm{C} / \mathrm{N}$.

Resultados semelhantes a estes foram encontrados por Boer et al. (2008) avaliando o $\mathrm{T}^{1 / 2}$ da massa de plantas de milheto, no Centro-Oeste brasileiro, sendo verificado um $\mathrm{T}^{1 / 2}$ de 105 dias para o N. Já no trabalho de Torres et al. (2005), onde foi avaliada a mineralização do $\mathrm{N}$, encontrou-se $\mathrm{T}^{1 / 2}$ de 100 dias para o milheto, 141 dias para o sorgo e 47 para área de vegetação espontânea (pousio). Os menores valores de $\mathrm{T}^{1 / 2}$ encontrados no presente estudo, principalmente para BRS 1501, sorgo e VE, quando comparados aos de Torres et al. (2005), podem ser decorrentes da maior precipitação $(305 \mathrm{~mm})$ frente à evaporação $(283 \mathrm{~mm})$, no decorrer dos 120 dias que os litter bags ficaram no campo. O balanço hídrico positivo $(22 \mathrm{~mm})$ pode ter acelerado a velocidade de decomposição da massa vegetal e, 
consequentemente, propiciado maior liberação dos nutrientes, principalmente o $\mathrm{N}$ (Tabela 4).

Tabela 4. Parâmetros dos modelos ajustados $\left(X=X{ }^{-k}{ }^{k t}\right)$ aos valores de nitrogênio, fósforo, potássio, cálcio e magnésio remanescentes de cada compartimento e valores de $\mathrm{r}^{2}$ de cada planta de cobertura.

\begin{tabular}{|c|c|c|c|}
\hline & \multicolumn{3}{|c|}{ Parâmetros da equação de decomposição } \\
\hline & $\mathrm{k}\left(\mathrm{g} \mathrm{g}^{-1}\right)^{(1)}$ & $\mathrm{T}^{1 / 2}(\operatorname{dias})^{(2)}$ & $\mathrm{r}^{2}$ \\
\hline & \multicolumn{3}{|c|}{ Nitrogênio } \\
\hline ENA 2 & $0,0067 *$ & 103 & $0,70 *$ \\
\hline BRS 1501 & $0,0096^{*}$ & 72 & $0,77 * *$ \\
\hline Sorgo & $0,0091 * *$ & 76 & $0,84 * *$ \\
\hline \multirow[t]{2}{*}{$\mathrm{VE}$} & $0,0539 *$ & 13 & $0,91^{*}$ \\
\hline & \multicolumn{3}{|c|}{ Fósforo } \\
\hline ENA 2 & $0,0086^{* *}$ & 81 & $0,72 * *$ \\
\hline BRS 1501 & $0,0178 * *$ & 39 & $0,78^{*}$ \\
\hline Sorgo & $0,0132 * *$ & 53 & $0,77 *$ \\
\hline \multirow[t]{2}{*}{ VE } & $0,0363 * *$ & 19 & $0,77 *$ \\
\hline & \multicolumn{3}{|c|}{ Potássio } \\
\hline ENA 2 & $0,1084 *$ & 6 & $0,99 *$ \\
\hline BRS 1501 & $0,1222 *$ & 6 & $0,99 *$ \\
\hline Sorgo & $0,0737 *$ & 9 & $0,99 *$ \\
\hline VE & $0,1098 *$ & 6 & $0,98^{*}$ \\
\hline
\end{tabular}

* e ** significativos a 5 e $1 \%$ pelo teste de Tukey. ${ }^{(1)}$ Constante de decomposição, ${ }^{(2)}$ Tempo de meia vida.

$\mathrm{O}$ maior acúmulo de $\mathrm{N}$ foi verificado na palhada de milheto ENA 2 (Figura 2), independente da época de avaliação. Já os menores valores, dentre as plantas estudadas, foram encontrados para a VE, em todas as épocas de avaliação, com exceção ao tempo zero, onde a VE apresentou teor de $\mathrm{N}$ estatisticamente igual ao do BRS 1501. Pela avaliação dos teores de $\mathrm{N}$, desde a retirada do primeiro litter bag (tempo de 10 dias) até a retirada do último (120 dias), percebe-se que o padrão apresentado para este macronutriente teve maiores valores para o ENA 2, seguidos do sorgo, BRS 1501 e VE (Figura 2). Este padrão demonstra grande potencial de acúmulo de $\mathrm{N}$ para os milhetos e o sorgo em detrimento a $\mathrm{VE}$, que representa a área em pousio, com destaque para o ENA 2, que ao término dos 120 dias, ainda apresentava $75 \mathrm{~kg} \mathrm{ha}^{-1}$ de $\mathrm{N}$ na massa seca remanescente, contra $30,08 \mathrm{~kg} \mathrm{ha}^{-1}, 46,95 \mathrm{~kg} \mathrm{ha}^{-1}$ e $7,55 \mathrm{~kg} \mathrm{ha}^{-1}$, respectivamente, para o BRS 1501 , sorgo e a VE.

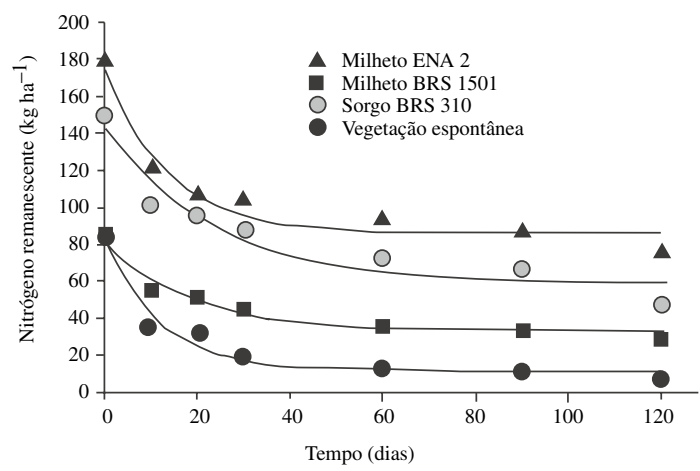

Figura 2. Teores de nitrogênio na biomassa seca remanescente das plantas de cobertura em avaliações realizadas no campo até 120 dias após a distribuição dos litter bags na superfície do solo.

De maneira geral, os teores de $\mathrm{N}$ acumulados pelas plantas de milheto ENA 2 e sorgo (Figura 2) foram superiores aos de muitos trabalhos encontrados na literatura (Torres et al., 2005, Carvalho et al., 2008, Boer et al., 2008). Tal padrão está relacionado à maior quantidade de massa seca produzida por essas plantas de cobertura no atual experimento (Figura 1), o que confere ao milheto ENA 2 e ao sorgo, grande potencial de retorno de $\mathrm{N}$ ao solo. Portanto, o plantio de culturas comerciais com sistema radicular mais superficial, tais como milho e oleráceas em geral, podem-se beneficiar do $\mathrm{N}$ aportado ao solo via decomposição dos resíduos destas plantas de cobertura. Para os teores de fósforo (P), observou-se padrão similar ao da biomassa seca. $\mathrm{O}$ maior $\mathrm{T}^{1 / 2}$ foi verificado para o ENA 2 (81 dias), e o menor para a VE (19 dias), sendo para o sorgo verificado $\mathrm{T}^{1 / 2}$ de 53 dias e para o BRS 1501, $\mathrm{T}^{1 / 2}$ de 39 dias (Tabela 4). Resultados semelhantes foram verificados por Boer et al. (2008), que observaram $\mathrm{T}^{1 / 2} \mathrm{de} 92$ dias para $\mathrm{P}$, em plantas de milheto.

Em relação ao acúmulo de $\mathrm{P}$, este apresentou padrão semelhante ao $\mathrm{N}$, com maiores valores para o ENA 2, seguidos do sorgo, do BRS 1501 e da VE, esta última com os menores teores, inclusive no tempo zero (Figura 3). Diferindo do N, o P apresentou uma liberação mais rápida, com menores $\mathrm{T}^{1 / 2}$ que o $\mathrm{N}$, com exceção à VE. Aos 10 dias após o corte, $36 \%$, $46 \%, 43 \%$ e $48 \%$, respectivamente, para o ENA 2, BRS 1501, sorgo e VE já haviam sido liberados, enquanto que para o N, $32 \%, 35 \%, 33 \%$ e $58 \%$, respectivamente, para o ENA 2, BRS 1501, sorgo 


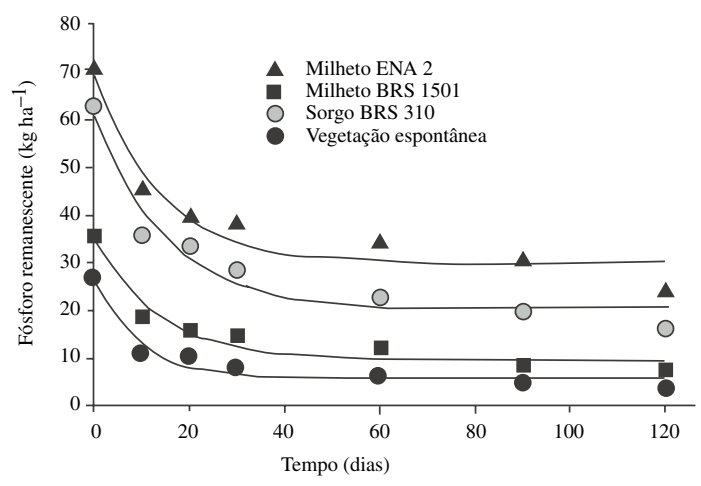

Figura 3. Teores de fósforo na biomassa seca remanescente das plantas de cobertura em avaliações realizadas no campo até 120 dias após a distribuição dos litter bags na superfície do solo.

e VE, já haviam sido liberados. A maior liberação de P no período inicial da decomposição está ligada à perda de $\mathrm{P}$ solúvel acumulado nos vacúolos dos tecidos vegetais (Buchanan e King, 1993).

Os menores $\mathrm{T}^{1 / 2}$ do $\mathrm{P}(\mathrm{VE}<\mathrm{BRS} 1501<$ sorgo $<$ ENA 2) estão de acordo com os menores teores de $\mathrm{N}$ e de biomassa seca (VE < BRS $1501<$ sorgo $<$ ENA 2) encontrados nas plantas de cobertura (Tabela 4). Este padrão demonstra que os fatores e mecanismos responsáveis pela decomposição da biomassa interferem diretamente na liberação de $\mathrm{P}$. Ou seja, a maior relação $\mathrm{C} / \mathrm{N}$ e maior proporção de colmos do ENA 2 acarretam em uma diminuição da velocidade de decomposição da biomassa quando comparado com as demais plantas de cobertura. Em contrapartida, a menor relação $\mathrm{C} / \mathrm{N}$ e a maior proporção de folhas no BRS 1501 e no sorgo (para $\mathrm{VE}$, menor $\mathrm{C} / \mathrm{N}$ e maior homogeneidade de folhas e colmos) além de aumentar a velocidade de decomposição da biomassa, propicia maior contato entre as folhas e o solo, culminando em maior área exposta para ação dos organismos decompositores, o que favorece uma maior taxa de decomposição e maior liberação de $\mathrm{P}$ dos resíduos culturais (GamaRodrigues et al., 2007).

Para o potássio $(\mathrm{K})$, verificou-se uma rápida liberação no início e, aos 40 dias, praticamente já não havia mais $\mathrm{K}$ na massa seca remanescente (Figura 4). A liberação ocorrida nos primeiros dias é atribuída ao fato do K não estar associado a nenhum componente estrutural do tecido vegetal das plantas e a mineralização não ser um pré-requisito para sua liberação, confirmando que a lixiviação é o principal mecanismo de transferência de $\mathrm{K}$ para o solo (Costa et al., 2005). Assim, à medida que a parte aérea das plantas de cobertura inicia o processo de secagem e se degrada, a concentração desse nutriente no tecido diminui drasticamente, pois o mesmo é facilmente removido em solução (Rosolem et al., 2003), após o rompimento das membranas plasmáticas (Malavolta et al., 1997). Assim, essa liberação acentuada para o solo confirma a alta reciclagem desse nutriente pelas gramíneas, favorecendo a próximo cultivo no processo de rotações e sucessões de culturas.

$\mathrm{O} \mathrm{T}^{1 / 2}$ para o $\mathrm{K}$ foi de $6,6,9$ e 6 dias, respectivamente, para ENA 2, BRS 1501, sorgo BRS 310 e VE (Tabela 4). Observou-se maior liberação de $\mathrm{K}$ para o milheto ENA 2 aos 10, 60, 90 e 120 dias após o corte, quando comparado com as demais plantas de coberturas. Nos tempos 20 e 30 dias após o corte, os valores de $\mathrm{K}$ acumulados foram estatisticamente iguais aos do sorgo. A VE apresentou os menores valores de $\mathrm{K}$ em todas as épocas de avaliação (Figura 4).

Quanto à liberação de nutrientes da matéria seca das plantas de cobertura, verificou-se que após 120 dias, que houve mineralização de 58, 65, 69 e $91 \%$ de N (Figura 2), de 67, 79, 74 e $85 \%$ de $\mathrm{P}$ (Figura 3) e de 99, 99, 99 e 99\% de K (Figura 4), respectivamente para o ENA 2, BRS 1501, sorgo e VE. Com a taxa de mineralização de cada nutriente das plantas de cobertura avaliadas, pode-se adequar o plantio das culturas comerciais subseqüentes, em função de suas necessidades para cada nutriente,

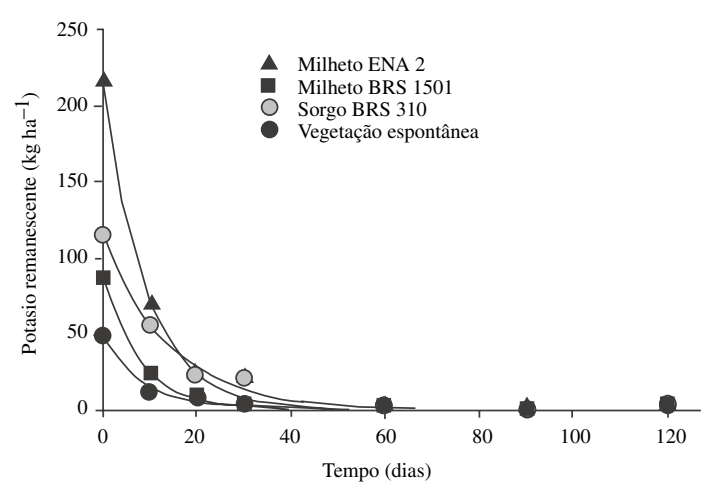

Figura 4. Teores de potássio na biomassa seca remanescente das plantas de cobertura em avaliações realizadas no campo até 120 dias após a distribuição dos litter bags na superfície do solo. 
diminuindo-se desta forma os custos com adubação mineral.

A utilização dos milhetos e do sorgo, como planta de cobertura para o solo, é recomendável pois a VE apresentou, a partir dos 10 dias após o corte, menores quantidades de massa seca que todas as plantas de coberturas, deixando mais rapidamente o solo descoberto, quando comparada com as demais plantas de coberturas. Em relação aos nutrientes remanescentes das plantas de cobertura, em função da época de avaliação, de maneira geral, verificaram-se maiores valores para o milheto ENA 2, seguidos do sorgo, BRS 1501 e da VE. Pode-se inferir que a utilização de qualquer uma das plantas de coberturas avaliadas (Milhetos ENA 2 e BRS 1501, e sorgo BRS 310) é mais eficaz no acúmulo e posterior liberação de nutrientes para o solo do que a VE, no pousio da área.

\section{Conclusões}

1. A cultivar ENA 2 apresentou maior relação $\mathrm{C} / \mathrm{N}$, maiores teores de lignina e maior $\mathrm{T} 1 / 2$ para massa seca, com degradação mais lenta, sendo mais recomendável para utilização como planta de cobertura do solo.

2. O ENA 2 também apresentou maior acúmulo e liberação mais gradativa de todos os macronutrientes avaliados, desde o corte, na maturação (tempo zero), até os 120 dias após. Já a vegetação espontânea, área em pousio, apresentou uma taxa de liberação de $\mathrm{N}$ e $\mathrm{P}$ mais rápida que as demais plantas de cobertura.

3. A utilização do ENA 2, do sorgo ou do BRS 1501 , nesta ordem, como plantas de cobertura e recicladoras de nutrientes é mais eficaz do que a vegetação espontânea (área em pousio).

\section{Literatura Citada}

Alvarenga, R.C.; Lara-Cabezas, W.A.; Cruz, J.C.; Santana, D.P. 2001 Plantas de cobertura de solo para sistema plantio direto. Informe Agropecuário, v.22, pp. 25-36.

Boer, C.A.; Assis, R.L.; Silva, G.P.; Braz, A.J.B.P.; Barroso,

A.L.L.; Cargnelutti Filho, A; Pires, F.R.

2008 Massa, decomposição e cobertura do solo ocasionada por resíduos culturais de três espécies vegetais na região Centro-Oeste. Revista Brasileira de Ciência do Solo, v.32, pp. 843-851.

Brancalião, S.R.; Moraes, M.H.

2008 Alterações de alguns atributos físicos e das frações húmicas de um Nitossolo Vermelho na sucessão milheto-soja em sistema plantio direto. Revista Brasileira de Ciência do Solo, v. 32, pp. 393-404.

Buchanan, M.; King, L.

1993 Carbon and phosphorus losses from decomposing crop residues in no till and conventional till agroecosystems. Agronomy Journal, v. 85, pp. 631-638.

Carvalho, A.M.; Bustamante, M.M.C.; Souza Junior, J.G.A.; Vivaldi, L.J.

2008 Decomposição de resíduos vegetais em Latossolo sob cultivo de milho e plantas de cobertura. Revista Brasileira de Ciência do Solo, v. 32, pp. 2831-2838.

Costa, G.S.; Gama-Rodrigues, A.C.; Cunha, G.M.

2005 Decomposição e liberação de nutrientes da serapilheira foliar em povoamentos de Eucalyptus grandis no norte fluminense. Revista Árvore, v. 29, pp. 563-570.

Gama-Rodrigues, A.C.; Gama-Rodrigues, E.F; Brito, E.C. 2007 Decomposição e liberação de nutrientes de resíduos culturais de plantas de cobertura em Argissolo VermelhoAmarelo na região Noroeste Fluminense-RJ. Revista Brasileira de Ciência do Solo, v. 31, pp. 1421-1428.

Geraldo, J.; Rossiello, R.O.P.; Araújo, A.P.; Pimentel, C. 2002 Diferenças em crescimento e produção de grãos entre quatro cultivares de milheto pérola. Pesquisa Agropecuária Brasileira, v. 35, pp. 1367-1376.
Kliemann, J.H, Braz, A.J.P.B.; Silveira, P.M.

2006 Taxas de decomposição de resíduos de espécies de cobertura em Latossolo Vermelho Distroférrico. Pesquisa Agropecuária Tropical, v. 36, pp. 21-28.

Malavolta, E.; Vitti, G.C.; Oliveira, S.A.

1997 Avaliação do estado nutricional de plantas: princípios e aplicações. Piracicaba: Potafos, 308p.

Paul, E.A.; Clark, F.E.

1989 Soil microbiology and biochemistry. San Diego, Academic Press. 275 p.

Redin, M.

2010 Composição bioquímica e decomposição da parte aérea e raízes de culturas comerciais e de plantas de cobertura do solo. Dissertação (Mestrado em biodinâmica e manejo do solo). Universidade Federal de Santa Maria, Santa Maria.

Rosolem, C.A.; Calonego, J.C.; Foloni, J.S.S.

2003 Lixiviação de potássio da palhada de espécies de cobertura de solo de acordo com a quantidade de chuva aplicada. Revista Brasileira de Ciência do Solo, v. 27, pp. 355-362.

Sylvia, D.M.; Fuhrmann, J.J.; Hartel, P.G.; Zuberer, D. 1998. A. Principles and applications of soil microbiology. New Jersey, Prentice Hall. 550 p.

Tedesco, M.J., Volkweis, S.J.; Bohnen, H.

1995 Análise de solo, plantas e outros materiais. Porto Alegre: UFRGS $188 \mathrm{p}$.

Teixeira, C.M.; Carvalho, G.; Silva, C.A.; Andrade, M.J.B.; Pereira, J.M.

2010 Liberação de macronutrientes das palhadas de milheto solteiro e consorciado com feijão-deporco sob cultivo de feijão. Revista Brasileira de Ciência do Solo, v. 34, pp. 497-505.

Teixeira, M.B.

2010 Teores de nutrientes na palhada e no solo, após o corte das plantas de milheto e sorgo. Dissertação (Mestrado em Fitotecnia). Universidade Federal Rural do Rio de Janeiro, Seropédica, RJ. 
Thomas, R.J.; Asakawa, N.M.

1993 Decomposition of leaf litter from tropical forage grasses and legumes. Soil Biology and Biochemistry, v. 25, pp. 1351-1361.

Torres, J.L.R.; Pereira, M.G.

2008 Dinâmica do potássio nos resíduos vegetais de plantas de cobertura no Cerrado. Revista Brasileira de Ciência do Solo, v. 32, pp. 1609-1618.
Torres, J.L.R.; Pereira, M.G.; Andrioli, I.; Polidoro, J.C.; Fabian, A.J.

2005 Decomposição e liberação de nitrogênio de resíduos culturais de plantas de cobertura em um solo de cerrado. Revista Brasileira de Ciência do Solo, v. 29, pp. 609-618. 